\title{
NOTAS BIBLIOGRÁFICAS
}

León-Portilla, Miguel. (Foreword Introduction and Notes.) Native Mesoameri. can Spirituality. Translation by Miguel León-Portilla, J. O. Arthur Anderson, Charles E Dibble and Munro S. Edmonson. Preface by Fernando Horcasitas. Paulist Press, New York, Ramsey, Toronto, 1980.

Contribución valiosa, como tantas otras suyas que lo honran, a la mayor comprensión del pensamiento y de los conceptos en torno a los más hondos problemas que se plantearon nuestros antepasados precolombinos, es el libro de Miguel León-Portilla, Native Mesoamerican Spirituality, mediante el cual sitúa inequivocamente el pensamiento de aquéllos en el orden de la cultura universal.

El autor define un concepto de espiritualidad que ha de ser marco de referencia a las cuestiones filosóficas planteadas en los textos por los antiguos mesoamericanos. Eso que por espiritualidad se entiende, sería el sentido del misterio, la percepción de lo que está más allá de lo sensorialmente percep. tible; en efecto, más allá de lo que aparece como solamente material, hay en el universo otras fuentes de significado, principios dinámicos, realidades supremas, con las cuales el hombre se puede comunicar cuando ha descubierto su sentido profundo.

Con exacta penetración, León-Portilla encuentra y pone de manifiesto a través de los textos de poetas, sábios y sacerdotes prehispánicos, el elevado nivel de espiritualidad alcanzado por los pueblos que habitaban esta porción de América antes de la conquista española. La mayor parte de los textos conservados están en lengua náhuatl y en lengua maya-quiché y maya-yucateca; datan posiblemente del periodo posclásico (950-1521).

Para la selección de tales textos, Léón-Portilla tomó en consideración precisamente los rasgos enunciados en su concepción de espiritualidad; es así como su atención se enfoca a los himnos, poemas religiosos y reflexiones filosóficas de autores anónimos o específicos de aquel mundo espiritual.

Después de la introducción general que proporciona al lector un informe crítico acerca de las culturas mesoamericanas y sobre los textos que en este libro se incluyen, el autor los agrupa en seis partes, de acuerdo con su tcmática y con su significado.

La parte primera se ocupa de la Antigua Palabra. Es a fray Andrés de Olmos y a fray Bernardino de Sahagún a quienes debemos la más larga colección de Huehuetlatolli. Los que están aquí publicados, son discursos de los antiguos que se tomaron del Códice Florentino; introducen al lector en ciertos aspectos de la vida diaria de los aztecas, en especial en lo que concierne a ideas y prácticas morales. Se incluyen las palabras con que el padre amonesta a su hija cuando ha llegado ésta a la edad de la discreción; la respuesta de la 
noble madre diciendo a su hija tiernas palabras, para que siempre recuerde el discurso de su padre; el discurso del padre con el cual amonesta a su hijo a que lleve una vida humilde y adquiera sabiduría propia, de manera que pueda ser complaciente con los dioses y con los hombres; la exhortación del padre a su hijo para inducirlo a la castidad, y otros textos que se refieren a la educación impartida en el Calmécac.

La parte segunda trata de los mitos de Creación. Con excepción de las ya publicadas por Dibble y Anderson (Florentine Codex), que el autor de este libro modifica con el objeto de ofrecer textos más fieles al original, en esta, como en otras partes, las traducciones al inglés son de León-Portilla. En lo que toca al maya-quiché, usa la traducción del Popol Vuh hecha por Munro S. Edmonson.

Los hablantes de lengua náhuatl llamaban Teotlatolli, divinas palabras y Teocuicatl, cantos divinos, a lo que hoy describimos como mitos. Relatos en lengua maya-quiché y en lengua náhuatl refieren los varios nacimientos y colapsos del mundo; las sucesivas creaciones de distintas clases de seres humanos; el descubrimiento del maiz. Los textos usados en esta parte fueron seleccionados del Popol Vuh (Libro del Consejo), del Códice Chimalpopoca, de los Anales de Cuauhtitlán y del Texto Mixteco de Cuilapa, con el objeto de mostrar el paralelismo de los mitos en las culturas maya, náhuatl y mixteca y corroborar asi la unidad de la civilización mesoamericana.

A la historia del sumo sacerdote Quetzalcóatl, señor de los toltecas, se dedica la parte tercera. La fascinante historia del legendario Quetzalcóatl, riquísima en significados simbólicos, es narrada por León-Portilla a través de los textos de Sahagún y de los Anales de Cuauhtitlán, que describen las hazañas del hombre-dios en el Altiplano Mexicano, el engaño de que es víctima y su huida o desaparición; también trata acerca de su presencia entre los pueblos maya-quiché y maya-yucatecos, bajo el nombre de Gucumatz y Kukulkán.

El dogma oficial y las dudas de los sabios acerca de lo que ocurre después de la muerte es el tema que unifica los textos de la parte cuarta. Dos posiciones, la oficial, de mayor rigidez, y la especulativa, con más flexibilidad, se revelan por medio de los textos elegidos por León-Portilla. El dogma oficial, tomado principalmente del Códice Florentino, exalta la muerte del guerrero en la batalla, las víctimas sacrificadas y las mujeres muertas en parto; todos estos muer tos iban para siempre a los cielos, a la casa del dios solar. En dichos textos se habla también de los sitios a donde llegaban los muertos: el Mictlan, lugar de muertos; el Ximoayan, lugar de los descarnados, y el Tocenpopolihuayan, nuestro lugar común en donde nos perdemos. Se hace referencia también al Tlalocan, paraíso de Tláloc.

En contraste con el dogma, otros poemas individuales expresan, más libremente, los conceptos, dudas y especulaciones en torno a la vida y a lo que ocurre después de la muerte. En éstos, es frecuente la reflexión acerca de lo transitorio de la vida, de que es pasajera como un sueño y que no es posible afirmar nada acerca del más allá, de lo que sucede después de la muerte Muchos de tales poemas fueron seleccionados de la Colección de Cantares Mexicanos. 
En la parte quinta y bajo el enunciado: "Poesia anónima religiosa y otros textos relacionados", Miguel León-Portilla pone ante nuestros ojos los múltiples significados de los poemas. Por un lado su función unificadora como medio de comunicación humana; los poemas, los cantos, eran entonados en público. Otro aspecto es el de la composición formal de tales poemas y cantos; ritmo y medidas que sutilmente el autor conserva en sus traducciones al inglés. Señala también las formas literarias con las cuales estos poemas se constituyen: uso de metáforas y de conjuntos de metáforas de manera que al leerlas "uno entra a un jardín florecido en donde una magnífica variedad de gemas, plantas, pájaros y colores dan nuevos significados a todo lo que nace y existe en la tierra"; frases reiterativas y palabras de principio y de final, maneras para persuadir que una idea o un sentimiento se han cumplido.

Tengo para mi que es la parte más reveladora de la espiritualidad mesoamericana; en los textos se descubre, gracias a León-Portilla, el significado esencial de su contenido. Se habla de los dioses y de su origen, de sus atributos y de sus poderes; del concepto abstracto de divinidad; de lo que es bueno y malo en la tierra; del sentido de la amistad; de lo que son y de lo que no deben ser esos hombres excepcionales: los toltécatl, artistas; los tlacuilos, pintores; los amantécatl, artistas de las plumas, y de otros más; del sentido de la guerra y de la creación de los ciclos de tiempo.

Se incluyen en esta parte himnos anónimos, poemas y cantos de los conservados por Sahagún en los Códices Matritenses y Florentino; otros son de la Colección de Cantares Mexicanos y de los Anales de la Nación Mexicana; Jos textos mayas proceden del libro de Canciones de Dzitbalché y del libro de Ghilam Balam de Chumayel.

La sexta y última parte se compone de los poemas del rey y sabio de Texcoco, Nezahualcóyotl, y de los de otros veinte autores, cuyos nombres ha sacado de la oscuridad Miguel León-Portilla. En la poesía de Nezahualcóyotl, la más conocida de las aqui publicadas, se encuentran reflexiones en torno a la fugacidad de lo que existe en la tierra; a los misterios que rodean a la muerte; a la posibilidad de decir palabras verdaderas, al propósito y el valor de la acción humana y a la inescrutabilidad del Supremo Dador de Vida.

Investigación acuciosa y paciente del autor, en parte ya publicada (Trece poetas del mundo náhuatl y "The Chalco Cihuacuícatl of Aquiauhtzin") permite ahora reconocer la identidad de estos poetas, entre los cuales se cuenta el nombre de una mujer: Macuilxochitzin.

Abundantes y eruditas notas propician en el lector occidental una mejor aproximación a los esotéricos textos de los poetas prehispánicos.

Miguel León-Portilla es uno de los grandes creadores de la cultura nacional; sus investigaciones, estudios y traducciones han puesto de relieve el nivel cultural al cual llegaron nuestros antepasados indígenas; ahora trasciende, una vez más, las fronteras del español, para llevar, a los que hablan en distinta lengua, el mensaje universal de la espiritualidad de nuestros pueblos antiguos.

B. de la F. 
Sharp, Rosemary. "Chacs and Chiefs. The Iconology of Mosaic Stone Sculp. ture in Pre-Conquest Yucatán, Méxi. co". Strdies in Pre-Columbian Art and Archaeology, No, 24, Dumbarton Oaks, Washington, D. C., 1981 .

Este libro es el resultado de una investigación original en el que se buscan vincular ciertos elementos arquitectónicos, como son las grecas escalonadas y las máscaras, con la política de un periodo específico, el Epiclásico. Debido a la carencia de investigaciones que busquen relacionar la arquitectura con la ideología, la importancia de esta publicación es evidente. La autora cuenta con otros artículos sobre temas semejantes, entre los cuales sobresale el publicado en el libro Middle Classic Mesoamerica, y que lleva como título: "Architecture as Interelite Comunication in Preconquest Oaxaca, Veracruz and Yucatan."

El mosaico de piedra aparece en el Epiclásico (periodo que abarca aproximadamente de 650 a 1000 d.C.) en varios sitios de Yucatán y de Oaxaca, así como en El Tajín; de hecho la autora considera que es un elemento diagnóstico para este periodo y que, por semejanzas en diseños complejos de grecas, puede indicar una relación estilística y quizá ideológica entre varias regiones de Mesoamérica como son las de Oaxaca, Veracruz y el norte de Yucatán.

Rosemary Sharp inicia su estudio con dos formas muy empleadas: la forma de $\mathbf{T}$ y la greca escalonada; ambas se emplean no sólo en la arquitectura, sino también en la cerámica, pintura y escultura. La importancia de la greca escalonada estriba, según la autora, en su multiplicidad simbólica, de allí su persistencia en el tiempo y su aparición en contextos históricos. Agrega que, por lo menos en el Epiclásico, simbolizaba, entre otras cosas, a la Serpiente Emplumada.

Al referirse a las máscaras de mosaico del norte de Yucatán anota sus semejanzas con el Dios Narigudo o Dios B de los códices; sin embargo hubiera sido también de interés que concretara las diferencias entre las máscaras de Chac del estilo Puuc y las máscaras que se cree representan a Itzamná y que se usan en los estilos Río Bec y Chenes.

Después de un estudio de la función de las máscaras relacionadas con los gobernantes mayas, de los Chacs y de los jefes mayas en cuanto a la manera que desempeñaban sus funciones, la autora concluye que los mosaicos de piedra, con su temática particular, reflejaban un nuevo orden correspondiente a una época difícil de transición. En este nuevo orden "se regresó a un arte más religioso que acentuaba las fuerzas naturales: al mismo tiempo que había un intento de desarrollar un modelo simbólico para la división del poder" (p. 19). Es decir, en última instancia el modelo simbólico de la rotación del poder entre los dioses, específicamente entre los Chacs, se copió en el ámbito real de la política.

El libro está acompañado de ilustraciones que complementan los conceptos que la autora quiere comunicar y que, como puede constatar el lector por lo 
dicho anteriormente, son de gian interés para el estudio de la arquitectura prehispánica.

N. G, S.

\begin{abstract}
Benton, Elizabeth, ed. "Mesoamerican Sites and World-Views", A Conference at Dumbarton Oaks, 1976, Dumbarton Oaks Research Library and Collections, Trustees for Harvard University, Wash. ington, D. C, 1981 .
\end{abstract}

En la reunión de la Dumbarton Oaks, en 1976, se propuso abordar tres problemas fundamentales: a) ¿Cuáles elementos del paisaje han actuado en la selección de los lugares donde se fundaron los sitios prehispánicos? b) ¿Cuál fue la relación entre los edificios y esos elementos (como la orientación de aquéllos y las alteraciones de éstos) ? c) ¿Qué significado tuvieron esos elementos y esa relación en la visión del mundo y en el pensamiento de los antiguos constructores?

Para acercarse a ese tema se reunieron estudiosos de disciplinas diversas y afines, arqueólogos, etnohistoriadores, etnólogos, arquitectos, arqueoastrónomos e historiadores del arte. El libro que se publicó se compone de una selección de las ponencias con las discusiones a que dieron lugar, Entre las diversas intervenciones, escogi dos particularmente sustanciales, la de la arqueóloga Doris Heyden del Instituto Nacional de Antropologia e Historia y la de la doctora Linda Schele de la Universidad de Tejas.

Doris Heyden nos permite vislumbrar el papel que tuvieron ciertos elementos naturales del paisaje para la fundación y el desarrollo no solamente de la gran metrópoli teotihuacana, sino probablemente también para muchos otros sitios, como un reflejo de la visión del mundo que tenían los mesoame. ricanos, aparte, claro está, de ciertos recursos naturales que fueron económica o estratégicameñte determinantes. Es un valioso estímulo para acercarnos a sitios hasta ahora desdeñados o para reconsiderar otros supuestamente bien conocidos.

Por su parte, Linda Schele nos presenta el caso de Palenque como un intento para integrar actos humanos en el tiempo y en el espacio cósmicos, en el afán de justificar y fundamentar el poder de un linaje reinante sobre la población súbdita y en el marco del área maya en general.

Doris Heyden, con su ponencia, "Caves, Gods, and Myths: World-View and Planning in Teotihuacan" (páginas 1-41) apoyó su tesis en un ejemplo particularmente significativo: la cueva que se encuentra abajo de la pirámide del Sol en Teotihuacan. Fundamentó sus argumentos en datos tomados del material arqueológico, de las crónicas de los siglos xvi y XVII, de los códices, de los informes etnográficos y de su propia experiencia.

Nos ofrece primero una descripción de esa cueva descubierta casualmente en 1971; la ilustra con planos y dibujos de secciones y detalla su configuración 
con la entrada al pie de la pirámide del Sol; su largo tunel y su cámara terminal en forma de flor de cuatro pétalos. Nos presenta a continuación el santuario primitivo de la fase Patlachique que se elevó sobre ella y nos ubica ese lugar de culto en el interior de la pirámide que la recubrió. Desgraciadamente, las informaciones quedan truncas por un saqueo que dejó muy poco mobiliario in situ y que destruyó gran parte de los vestigios provenientes del culto que se rendia allí; por lo tanto, es sobre todo afuera de la cueva misma que Doris Heyden buscó los elementos para entender el significado de su sacralización. Supone que la erección de la pirámide del Sol sobre tal sitio y sobre el santuario primitivo significó una ampliación colosal de la sacralidad del lugar En vista de la importancia primordial de esa pirámide para toda la ciudad, considera que la cueva era el axis mundi de Teotihuacan y que las peregrinaciones que originó el santuario determinaron la gigantesca labor de eregir la magna pirámide, contribuyendo así directamente al desarrollo de la urbe Eso nos hace recordar las ciudades medievales europeas que prosperaron alrededor de las catedrales a las cuales acudían grandes masas de peregrinos. En la iconografía teotihuacana encuentra to que podría ser una ilustración de un mito sobre la cueva como centro del mundo teotihuacano: la figura central del mural de Tepantitla se yergue sobre una cueva de la cual mana agua.

Para determinar el significado de la cueva, acude a los mitos considerando que "los hombres, cuando construyen su casa o su ciudad alrededor de algún centro -en este caso, la cueva y la pirámide--, crean su mundo a la imagen del cosmos, en imitación de los dioses, tales como se los enseñan los mitos". Reconoce, claro, que la visión del mundo operante en el centro de México durante el Clásico quedará totalmente hipotético para nosotros. Sin embargo, no puede dejar de referirse a los mitos de épocas posteriores, reflejos de tradiciones orales heredadas, para intentar reconstruir el pensamiento teotihuacano. Parte de la premisa de que todas las fuerzas naturales eran consideradas como seres animados para los mesoamericanos. Revisa el significado de cada uno de esos elementos, como el sol, la luna, el agua, el fuego, y también las plantas y los elementos geográficos, deteniéndose largamente en las cuevas. Nos demuestra cómo las cuevas eran consideradas lugares de creación de dioses, hombres y plantas vitales, sedes de oráculos y seno materno para ciertos ritos funerarios, en relación con divinidades de la tierra, del agua y de la fertilidad y cómo siguen siendo consideradas como tales todavía hoy en día en muchas partes del pais.

Se detiene sobre el cambio del centro geográfico, político, económico y religioso de Teotihuacan, desde la pirámide del Sol hacia el sur y el gran complejo de la Ciudadela. Según la autora, este traslado podria reflejar un cambio en el centro mismo de la religión con un desplazamiento de dioses agrarios, personificando la tierra y el agua, en favor de divinidades relacionadas con el comercio, el tributo y quizás la guerra, reflejo a la vez de una transformación en la sociedad.

Finalmente, enfatiza la importancia fundamental de los mitos y de la planificación de Teotihuacan en la tradición del centro de México, con persis- 
tencias determinantes en la cultura tenochca y aun hasta en la de nuestros días.

En la discusión ulterior concuerdan los participantes sobre la dificultad, por ahora, de relacionar el significado de la cueva abajo de la pirámide del Sol con la indiscutible importancia de ésta en la determinación de los ejes que ordenaron estrictamente toda la planificación de la gran urbe. Se sugiere similitudes con cuevas-santuarios en Chiapas, con sitios de Puebla (Totemi. huacan), de Morelos (además del lugar aludido en la página 38, existe por lo menos otro más, de amplia extensión, en Iztamatitlan) y de Yucatán (Chichen Itzá) y con el templo monolítico de Malinalco. Se deja entrever la posibilidad de encontrar otras numerosas cuevas abajo de un gran número de edificios de Teotihuacan.

Por andar en un terreno todavía muy novedoso y erizado de incógnitas, la autora no sigue siempre un ordenamiento muy estricto en la presentación de su argumentación y de su profusa documentación. Así, cuando concluye (página 28) que "la importancia geomántica, mítica y religiosa del tema cuevatemplo era tan grande que estuvo incorporado y sobrevivió en los mitos y en el pensamiento con que se erigieron las ciudades posteriores del centro de México", no encontramos en realidad tal demostración en su exposición. A1 dar como ejemplo de persistencia la planificación de Tenochtitlan, la autora habla de la "recreación" del mito, en particular del de la creación del Quinto Sol, pero no toca el tema de la cueva.

Este estudio pionero no pudo llegar a conclusiones muy precisas.

Aun la importancia de que la cueva tuvo como lugar sagrado en el desarrollo de Teotihuacan queda sujeto a discusión, como lo expresa uno de los participantes de la conferencia, ya que la pirámide del Sol puede haber significado tanto una ampliación monumental del santuario primitivo como su destrucción, a semejanza de lo que ocurrió con la religión de Akenatón en Egipto.

Los ejemplos que da de cultos en cuevas en diferentes regiones y épocas relacionan esos lugares con la lluvia y la tierra y, sin llegar a conclusiones explícitas, la autora parece suponer que la cueva y la pirámide, por lo menos el origen, eran dedicadas a esas divinidades agrarias, pero no intenta explicar por qué, ulteriormente, los informantes de Sahagún, que la autora cita, reportaron que las pirámides eran dedicadas al sol y a la luna. $O$ sea, que en cierta medida regresamos al problema de la relación entre esta cueva y la orientación de los edificios teotihuacanos, determinada por fenómenos celes. tes. Doris Heyden reconoce, al respecto, que todavía no se dispone de un plan rigurosamente exacto de la cueva y de su orientación.

Pero lo importante aquí no era solucionar tal problema particular sino, como lo hace este entusiasta estudio, abrir un nuevo campo de investigación de la cultura teotihuacana, no para apartarse del "interminable determinismo económico" como pregona Peter Furst en la discusión, sino para conocer el pensamiento teotihuacano, ligándolo, como lo hace Doris Heyden, a la realidad económica y social que lo sustentaba.

Por su parte, Linda Schele principia su ponencia "Sacred Site and World. 
View at Palenque" (páginas 87-117), con una dilatada descripción del sitio de Palenque, de su contorno general y de la configuración topográfica de cada uno de sus sectores (páginas 87-95), para centrarse en la zona ceremonial ubicada alrededor del río Otolum, específicamente en los edificios mayores pertenecientes a los tres primeros gobernantes de Palenque durante el Clásico Tardío, cuando el sitio conoce un crecimiento explosivo, llegando a ser uno de los principales focos de creación del Clásico Tardío maya. Basa su exposición en un estudio cronológico de la arquitectura de Palenque que realizó con Robert Rands con datos provenientes de la cerámica, de los glifos, de los estilos y de las técnicas aplicadas, vertidos en un cuadro (página 111) que incluye la fecha de cada construcción y el gobernante al cual corresponde. Además de ese marco cronológico, fundamenta su exposición sobre un análisis de la planificación del sitio, sobre su interpretación iconográfica y epigráfica de los relieves relativos al ascenso y la muerte de sus dirigentes y sobre su identificación de los emblemas del sitio.

Considera a los tres primeros gobernantes del Clásico Tardio, Pacal el Grande, Chan-Bahlum y Kan-Xul, como los responsables de la historia oficial dinástica que proveyó de origen divino a la dinastía palencana y los que plasmaron en los glifos, la escultura y la arquitectura ese traspaso sobrenatural del poder, mientras que los sucesores se contentaron con afirmar su descendencia del linaje de Pacal el Grande.

Empieza con Pacal el Grande, su tumba y el templo de las Inscripciones. Reconoce en el personaje de la lápida del sarcófago, al gobernante al morir, entrando en el inframundo, con el sol muriendo. Dice que el templo mismo está orientado de tal forma que, para un espectador situado frente a él, el sol del solsticio de invierno parece entrar en el inframundo a través de la tumba real.

El monumento del sucesor, Chan-Bahlum, sería el templo de la Cruz. Sobre la lápida exterior occidental, identifica al dirigente cargando en sus manos al dios tripartito monstruo solar, en un gesto para ofrecerlo a la figura de la jamba oriental, el dios $\mathrm{L}$, uno de los principales dioses del inframundo. La orientación del templo lo relaciona también con el ocaso del solsticio de invierno. En esa circunstancia, los rayos solares penetran en el interior del templo e iluminan el relieve en donde Pacal a la izquierda (figura pequeña para representar a un difunto) carga al dios tripartito, frente a Chan-Bahlum a la derecha, y entre los dos el mismo motivo cruciforme de la lápida sepulcral del Templo de las Inscripciones. Al seguir su curso, el sol envía su último rayo sobre el relieve exterior oriental iluminando al dios $L$.

Para el tercer gobernante, Kan-Xul, la autora considera que utilizó la casa $\mathrm{C}$ del Palacio (en donde reconoce una representación del nacimiento y del ascenso de Pacal). Este sucesor hubiera erigido la torre en la esquina S-O para captar mejor el ocaso del solsticio de invierno atrás de la sepultura de su ilustre antepasado y establecer así una conexión directa con ella. Esta torre también "por implicación y proximidad" estaría en conexión con el templo de la Cruz de Chan-Bahlum. Nos dice, además, que desde la torre se divisa el ocaso del solsticio de verano en lineamiento con el templo XI 
que supone ser el edificio funerario de Kan-Xul, aunque advierte que su fecha es insegura.

Sigue con consideraciones menos detalladas sobre orientaciones diversas de otros edificios, en particular sobre los juegos de sombras, y subraya que el único caso que parece ser relacionado con el amanecer (al solsticio de invierno) es el templo del Sol: solamente en esa ocasión recibe los rayos solares en su interior. Por lo general, la orientación de los edificios estaría en conexión con el ocaso solar. Es así como toma sentido para el Rector la larga descripción preliminar de la configuración del terreno, para poder seguir a la autora cuando afirma que los palencanos escogieron esta zona del río Otolum para desarrollar su centro ceremonial, ya que la misma configuración del terreno permitía allí manipular los fenómenos visuales de la puesta del sol.

Por fin, nos ofrece una interpretación de los glifos emblema de Palenque, como el lugar donde mueren el sol y la luna.

Resumiendo su estudio, Linda Schele llega a las conclusiones siguientes:

I) Palenque estuvo planeado, en su apogeo, para utilizar el ocaso de los solsticios como elementos arquitecturales mayores y dramáticos, El ascenso al poder y la muerte de sus tres mayores gobernantes aparecen en los relieves asociados con la entrada del sol en el inframundo.

2) Los edificios que presentan los relieves detallando la mitología real están orientados de tal modo que re-crean esa mitologia, públicamente, en una escala cósmica cada año, eternamente, propiciando así un apoyo considerable al sistema político-religioso palencano.

3) El emblema de Palenque, como los edificios y los relieves aludidos, nos aclaran que las responsabilidades del poder real en Palenque eran definidos en relación con los cielos solares y el inframundo.

4) Los emblemas de Palenque sugieren una identificación del sitio como umbral occidental del inframundo, no solamente para los mismos palencanos sino para todo el mundo maya.

5) En Palenque, la visión del mundo que determina la posición y la función del hombre en general y del gobernante en particular, se vinculaba íntimamente con los fenómenos celestes, sobre todo con el sol y se expresaba a través de eventos observables públicamente, creados por la arquitectura y los relieves.

6) La institución real de Palenque era especializada en ritos y deberes ligados con la función atribuida a Palenque, a nivel de toda el área maya, como umbral occidental del inframundo, como lo expresan sus emblemas.

En la discusión posterior, se aclara primero que ese papel de portal occidental del inframundo no debe confundirse con el de una necrópolis "Luego, el intercambio de opiniones se cierra sobre un punto aparentemente tangencial a la exposición presentada, pero que resulta para un no-mayaísta muy significativa del valor de este trabajo. La autora considera, en base a su estudio epigráfico, que el hombre enterrado abajo del templo de las Ins- 
cripciones se llamaba Pacal y que murió a la edad de ochenta años, mientras que los estudios osteológicos realizados sobre sus restos concluyeron que se trataba de un individuo no mayor de cuarenta años al morir. La autora asegura que resuelve fácilmente esa discrepancia. Es un problema para los "dirt archaeologists" y no para los epígrafos.

Un error de su parte es imposible y por lo tanto quedan dos posibilidades. O la edad propuesta por los antropólogos físicos es errónea y el error se debe a que se trabajó mal,1 o la historia oficial escrita en Palenque no se ajustó a la realidad $y$, por ejemplo, reunió a dos hermanos en una sola persona.

Esta actitud cierra obviamente la puerta a toda discusión, tal como se debería dar en este tipo de reuniones y es sintomática en todo el artículo, en donde se nos ofrecen interpretaciones a veces muy controvertidas como si fueran hechos indiscutibles, sin poner a consideración en ningún momento los otros puntos de vista. $\mathrm{Y}$ es así que la autora omite toda mención a los trabajos del doctor Alberto Ruz Lhuillier, no solamente acerca de sus descubrimientos o de sus primeros estudios sobre el tema, pero aun acerca de sus nuevas interpretaciones epigráficas (como la edad y el nombre del gobernante enterrado en la tumba-pirámide).$^{2} \mathrm{Me}$ permito retomar aquí las palabras mismas del doctor Ruz Lhuillier acerca de esas controversias:3

Creo que todos los que hemos intentado descifrar esta inscripción, en algo o en mucho debemos habernos equivocado... Pero creo también que el camino que seguimos, el de la interpretación histórica de las inscripciones jeroglíficas mayas, es el bueno .... Sin embargo, para no equivocar el rumbo, debemos ser prudentes, no dejar de utilizar nuestra imaginación pero cuidándonos mucho de extraviarnos por los senderos de la fantasía.

Afirmaciones rotundas sobre puntos todavía discutibles y aún rechazables, basadas no sobre hechos comprobados sino sobre hipótesis, por atractivas que sean, tales afirmaciones además de prematuras, resultan peligrosas y restan seriedad científica a cualquier intento de desciframiento por bien intencionado y correctamente encaminado que esté.

Al confrontar las hipótesis de esos dos autores sobre la edả de "8 Ahau" - "Pacal", como se quiera llamar al ilustre palencano, constatamos que la discrepancia se origina sobre dos puntos todavía sin resolución definitiva: las fechas inscritas en el sarcófago se refieren a una o a dos series iniciales;

1 El examen osteológico realizado al descubrir el entierro fue completado por otro posterior sin modificación alguna en el dictamen, y no parece prudente rechazar tan a la ligera esos datos precisos. Ver nota 4, p. 92, en Alberto Ruz Lhuilliex, "Nueva Interpretación de ia Inscripción Jeroglifica en el Saroófago del Templo de las Inscripciones", pp. 87.94, in The Art, Iconography and Dynastic History of Palenque, pait. III, proceedings of the Segunda Mesa Redonda de Palenque, 1974, Precolumbian Art Research - The Robert Louis Stevenson School, Pebble Beach, California, 1976.

2 Alberto Ruz Lhuillier, op. cit, 1976.

3 Ibid., pp. 92-93. 
la fecha de la muerte es la segunda o la última de la serie grabada. La seguridad de la autora al respecto, en todo caso, nos parece sumamente precipitada.

Regresando al tema central de la conferencia publicada en el presente libro, hay interpretaciones de la doctora Linda Schele que me dejaron perpleja.

Los elementos arquitecturales que hubieran sido escogidos por el tercer gobernante para afirmar el origen divino de su poder (la torre del Palacio como conexión con el templo de las Inscripciones y el templo de la Cruz, los monumentos de sus dos antecesores por una parte, y por otra, el alineamiento -en realidad muy poco preciso, ver figura 6, página 102- del ocaso del solsticio de verano con el templo XI y la torre) son elementos que ya son retomados en el resumen que nos ofrece la exponente al concluir, indicando así implicitamente que para ella misma se tratan de hipótesis muy frágiles.

Como lo enfatiza Lindá Schele, los espectáculos creados con la orientación particular de ciertos edificios y los rayos solares en momentos determinados, tenían como propósito impactar al común de la población que podía observar por sí misma los fenómenos que venían a confirmar la relación mitológica de sus gobernantes con el inframundo occidental. Sin embargo, dudamos que el efecto de los últimos rayos solares sobre los relieves del templo de la Cruz podía ser efectivamente apreciado por los súbditos desde el pie del templo. La foto demostrativa ha sido tomada desde el vestíbulo del templo y no desde abajo. Además, en caso de que se podían ver los relieves a partir de los lugares accesibles a toda la población, queda otro problema para seguir a la autora en su demostración. En efecto, los fenómenos solares del solsticio de invierno asociados al templo de las Inscripciones y al templo de la Cruz no podían ser observados simultáneamente. Para ver el sol entrar en el inframundo a través de la tumba-pirámide se necesita situarse frente al templo de las Inscripciones $y$, de alli, se ve solamente la parte lateral y posterior del otro templo. Al inverso, desde la plaza del templo de la Cruz, ese mismo ocaso, único dentro del año, no creaba ningún efecto relevante en relación con el templo de las Inscripciones.

No creo que la autora suponga que las masas de creyentes se movilizaban rápidamente de un lugar al otro para no perder ninguna de esas dos "recreaciones" del mito. Quizás, la autora quiere dar a entender que el solsticio no era considerado en su estricta precisión de día único pero de varios días alrededor de la fecha, to que obviamente hubiera quitado solemnidad al evento. En todo caso, esa hipótesis de la manipulación del ocaso por parte de los dos grandes gobernantes hubiera sido más convincente si los templos de cada uno hubieran sido erigidos trente a frente para permitir la apreciación simultánea, desde un mismo lugar de los dos fenómenos aludidos. Ese mismo conjunto de los tres templos de las Cruces, al sureste del templo de las Inscripciones y del Palacio, no nos parece tampoco propicio para incorporar el ocaso a un plan unificador del centro ceremonial, tal como lo quiere demostrar Linda Schele. 
En conclusión, considero que este artículo resulta ser un intento válido para incorporar las interpretaciones epigráficas e iconográficas a la comprensión global del centro ceremonial, pero sin lograr todavía establecer relaciones claras entre éste y los elementos naturales del lugar escogido para levantarlo.

Es un claro ejemplo de las innumerables dificultades que se presentan todavia para poder resolver los problemas geománticos que proponia abordar la conferencia publicada en el presente libro.

M-A. H.

Parsons, Lee A Pre.Columbian Art. The Saint Louis Museum Collections. Harper and Row. New York, 1980 .

Al finalizar la segunda guerra mundial, el acaudalado señor Morton D. May empezó a dedicar parte de sus recursos en juntar obras de arte precolombino; formó así una colección, importante por la calidad artística de sus componentes y por la variedad de las culturas representadas. Gran parte de este conjunto fue donado recientemente al Saint Louis Art Museum de Missouri. Este donativo conforma el cuerpo principal de las colecciones del museo en este campo del arte ya que consiste en el $86 \%$ de las 3000 piezas, o sea unas 2580 y en ella está el origen de la presente publicación.

Como lo aclara el autor esta importante colección de arte, es una de las últimas grandes reunidas por un privado y cedidas a un museo norteamericano, ya que, antes de la segunda guerra mundial,. si bien las obras precolombinas estaban tomadas en consideración por las instituciones dedicadas a la antropología, en general no llamaban la atención, primordialmente como creaciones artísticas. La colección se fue formando cuando nació en EEUU un interés tardio por el arte precolombino. Aparentemente tal interés no nació de algún movimiento artístico particular sino de circunstancias ajenas al arte, mismas que cerraron algunos mercados de antigüedades y favorecieron o ampliaron otros. En realidad, este punto no nos es precisado por Lee A. Parsons, autor del libro que nos ocupa pero, en cambio informa de la razón por la cual este nuevo campo de acción para los coleccionistas y museos "conscientes" quedó cerrado cuando a fines de los sesenta el gobierno de Estados Unidos decidió apoyar las legislaciones latinoamericanas para la protección de su patrimonio arqueológico, al prohibir la importación de obras precolombinas; desde entonces quedaron en circulación legal solamente las piezas introducidas antes de estas nuevas disposiciones.

Obviamente, no se podía esperar encontrar en el texto alguna expresión de oprobio hacia el saqueo, pero es sorprendente la justificación, algo ingenua, que ofrece el autor sobre esta actividad de la cual él mismo es ajeno. El arqueólogo, nos dice Lee Allen Parsons, tiene poco acceso a las ofrendas funerarias y a los objetos suntuarios en general, porque éstos están raras veces encontrados en excavaciones cientificas; por lo tanto, acostumbrado a las piezas fragmentarias, no tiene la formación adecuada para analizar y clasificar 
las piezas enteras, cuando precisamente son estas últimas las que permiten a través de estudios iconográficos y estilísticos, conocer la religión y la ethos de las culturas carentes de escritura desarrollada. Implícitamente, según tal razonamiento, las excavaciones "no cientificas", si bien es cierto que sacan las obras de su contexto, vienen sin embargo a completar la labor arqueologica al generar esas amplias colecciones indispensables al conocimiento de las culturas prehistóricas. No debiera haber, por lo tanto, razones para lamentar demasiado el saqueo. Pero para aceptar tal consuelo tendríamos que olvidar por qué el saqueador no comparte la mala suerte del arqueólogo, mala suerte que no proviene evidentemente de alguna fatalidad sino de los propósitos opuestos a cada uno de los proveedores de obras antiguas. Cómo olvidar que para cada pieza artística que viene a entrar en esas colecciones, quedó una multitud de informaciones y objetos rechazados y destruidos por no tener valor comercial alguno.

Pero si existe tal tráfico de antigüedades, es de alegxarse que una colección de esa amplitud y calidad pare en un museo para ser exhibida a la luz pública, y en eso reside el mayor mérito del presente libro. Es, sin embargo, también aquí en donde se encuentra su mayor falla ya que las personas más interesadas por él verán sus esperanzas frustradas. En efecto, de las tres mil piezas anunciadas que integran las colecciones del museo, nos son presentadas solamente quinientas, o sea una de cada seis; además, los estudiosos en estilos e iconografía no disponen de dato alguno sobre la mayor parte de la colección no publicada. El autor no precisa ninguno de los criterios aplicados para realizar su selección. Así, por ejemplo, de las mil quinientas piezas del Preclásico Medio mesoamericano de que disponía, apenas 54 están dadas a conocer y no hay modo de saber si las otras obras fueron descartadas por fragmentarias, repetitivas, atípicas, o cualquiera otra razón. Esta selección tan drástica fue inevitable no solamente por las exigencias y restricciones de un libro lujosamente diseñado, si no sobre todo porque el autor se propuso presentar la colección en su amplia diversidad, dirigiéndose a un público muy abierto. Aprovechando la variedad de las piezas disponibles, el autor intenta ofrecer una visión general del arte de las civilizaciones avanzadas indígenas del Nuevo Mundo, que se desarrollaron desde 1200 antes de Cristo hasta la conquista española. Así, a pesar de que la colección reúne sobre todo objetos mesoamericanos, no deja de tener también obras de las civilizaciones andinas además del área intermedia. En este panorama, que pretende ser lo más exhaustivo posible, sorprende la ausencia de testimonios de las culturas del suroeste y sureste de los Estados Unidos, descartadas sin ninguna explicación (solamente se mencionan de paso las culturas tardias Temple Mound, página 2). Quizá esa carencia se deba al desinterés del coleccionista principal hacía el pasado de sus compatriotas indios o quizá a cualquier circunstancia aleatoria del mercado de antigüedades.

Como ya lo atestigua la selección misma de los objetos, el autor se dirige ante todo a un público no especializado, estimando que la importancia de la colección de por sí atraerá la atención del especialista. Por lo tanto, en su introducción, se preocupa por dar a sus lectores una visión rápida y global 
del desarrollo de la civilización en el Nuevo Mundo, con los inevitables esquematismos y simplificaciones que permitan al lector entender el valor testimonial de las obras de arte expuestas. No viene al caso, por lo tanto, detenernos en esta presentación previa. Dos puntos, sin embargo, son de llamar la atención. Al definir (página 2) las élites que orientaron la creación artística, el autor se refiere a dinastías hereditarias gobernantes. Tal definición, influida por el esquematismo del texto puede engañar a un lector no advertido que podría tomar eso como un hecho comprobado por la axqueología que hubiera así triunfado de sus limitaciones en definir las superestructuras de las sociedades prehistóricas. El otro punto es cuando, al subrayar el corte violento operado por la conquista española en las civilizaciones inca y azteca, el autor (página 13) vaticina que, de haber dispuesto de más tiempo para su desarrollo autónomo, esas dos civilizaciones se hubieran encontrado en un choque frontal y excluyente la una de la otra. Tal apreciación es un anacronismo que se remite a la visión bipolar de nuestro planeta, al estilo de la guerra fría actual.

Después de su ojeada general, Lee Parsons aporta algunos detalles sobre las técnicas desarrolladas en el arte precolombino, en particular sobre la metalurgia y la cerámica. Subraya la importancia del comercio de objetos de lujo dentro de cada área mayor y la existencia de contactos entre éstas Prosigue con la definición de las tres áreas mayores, Mesoamérica, Andes Centrales y Área Intermedia y sus subdivisiones que sirvieron para ordenar la colección ilustrándolas con tres mapas.

El cuerpo de su trabajo lo subdivide en tres áreas mayores para las cuales precisa las subáreas y detalla los principales horizontes culturales con tablas cronológicas, tan esquemáticas como el texto. Las piezas quedan así agrupadas según un orden claro por regiones y periodos.

Cada objeto está ilustrado por una buena foto en negro y blanco, además de sesenta fotos a color que resaltan la belleza de algunos de los objetos. Las cédulas detallan la naturaleza de la obra, su atribución geográfica y cultural, su posición cronológica (época y fechas), el o los materiales de que está hecha, Ia fuente de adquisición por parte del museo, el número de catálogo, las dimensiones y, eventualmente, la colección a la cual perteneció anteriormente y los Iugares en donde ya había sido publicada. Al respecto, resalta el hecho de que solamente 24 piezas ya habian sido dadas a conocer, lo que ilustra la importancia de esa colección prácticamente inédita.

En esas cédulas volvemos a encontrar la misma falla del libro, que por ser destinado a un amplio público, descarta deliberadamente las informaciones útiles para el especialista. El mismo autor reconoce que renunció a todas las citas bibliográficas que no fueran estrictamente necesarias. De ese modo las identificaciones culturales, geográficas y cronológicas nos están dadas con raras excepciones, sin justificación, sin la información en que se apoya. Para numerosas piezas, estilos o tipos perfectamente conocidos, tales precisiones quizás hubieran sido supérfluas pero hay casos en que eran indispensables en particular para saber si tal lugar de procedencia puede ser tomado como tal o como simple aproximación en base a comparaciones estilísticas. Es el 
caso especialmente para la colección de George Pepper comprada por Morton D. May que representa prácticamente la mitad de las piezas adquiridas por ese coleccionista, y consiste, sobre todo, en objetos atribuidos a Tlatilco y Las Bocas, además de unos de Teotihuacan, de Chupicuaro y del Golfo. George Pepper realizó trabajos arqueológicos en el suroeste de los Estados Unidos a final del siglo pasado y principios del actual, o sea que su actividad estuvo lejana a esos tres sitios preclásicos y anterior a su descubrimiento. Hubiera sido necesario, por lo tanto, saber cuándo y cómo George Pepper adquirió esas piezas para aclararnos si las de su colección tienen un origen geográfico preciso o solamente un parentesco estilístico evidente. También hubiera sido útil que el autor apoyara con referencias sus fechamientos, ya que para cada objeto ofrece fechas que no siempre concuerdan con precisión con las secuencias propuestas. Es el caso, por ejemplo, de las obras de la fase Comala de Colima, que el autor sitúa en fechas algo más tempranas que las determinadas por la doctora Isabel Kelly. ${ }^{1}$ En general, el autor es más circunspecto en cuanto a lugar de origen y fechamiento cuando se trata de los Andes Centrales y del Área Intermedia que cuando son piezas mesoamericanas, con las cuales está más directamente familiarizado ya que realizó trabajos arqueológicos en la costa pacífica de Guatemala, y tuvo una participación notable en la definición del arte postolmeca y del horizonte Izapa. Obviamente, esas deficiencias señaladas en las cédulas se deben a las restricciones que fueron impuestas a la publicación y no a los conocimientos ampliamente reconocidos del autor.

No podríamos desglosar aquí las obras presentadas en el libro; sólo haremos algunas anotaciones. El horizonte Preclásico Medio con los estilos Tlatilco y olmeca es el más representado en las colecciones del museo, pero es aquí que la selección fue la más drástica. Es particularmente lamentable el conjunto de cien piezas provenientes del saqueo de un montículo en San Pablo, Morelos, antes de las excavaciones de David Grove, ya que sólo aparecen ocho de ellas, entre las cuales llaman la atención la figura de un guerrero (figura 26) y una extraña figurilla trípode (figura 27). Destacan dos vasijas olmecas, una olla con una agarradera interior hueca, excepcional (40) y un vaso cilíndrico con un glifo representando una mano (39); una máscara olmeca tallada con una extrema sensibilidad podría provenir de un conjunto descubierto en Arroyo Pesquero y disperso en varias colecciones privadas. Hay varias piezas identificadas como olmecas y postolmecas para las cuales se da el origen preciso de Tenenexpan al norte de la ciudad de Veracruz, sin que se aclare sobre qué se basa tal precisión.

Del occidente de México, una tercera parte de la colección está presente. Son interesantes cuatro piezas de la fase Comala: una vasija cilíndrica con decoración en relieve, que según la doctora Isabel Kelly podría reflejar alguna relación lejana con Teotihuacan ${ }^{2}$ (figura 113); un cántaro en forma de

1 Isabel Kelly, "Ceramic sequence in Colima: Capacha, an early phase", Anthropological Papers of the University of Arizona, 37, The University of Arizona Press, Tucson, 1980.

2 Ibid., p. 7. 
pirámide circular (figura 116) que nos recuerda la arquitectura circular de la zona de Etzatlan descubierta por Phil $\mathrm{C}_{\text {. Weigand; }}{ }^{3}$ otro cántaro con decoración al negativo (figura 114), y una figura excepcional en forma de yugo (figura 117).

Entre los objetos de Teotihuacan, sorprende una vasija trípode con tapa en forma de pájaro (figura 136); una de las máscaras presenta las incrustaciones completas (150) y un fragmento de fresco (figura 153) atestigua de los destrozos que causa el saqueo a los mismos edificios. Relacionándolo con uno similar encontrado en la pirámide del Sol, el autor nos presenta el con. tenido completo de un escondite adentro de una tumba, con cincuenta y ocho figuras excéntricas en obsidiana, encontrado en Cuautitlán (figura 155).

Del arte mixteco notamos la presencia de una vasija en forma de mono, en onix, perteneciente anteriormente al Museum of Primitive Art, de New York (figura 173) y un fragmento de fresco proveniente del limite entre Oaxaca y Veracruz (figura 182). Entre unas cuantas piezas aztecas figura una de las escasas esculturas en madera rescatadas (figura 188).

De la centena de urnas zapotecas pertenecientes al museo, la mitad está presente para ilustrar la evolución de este género, con varios conjuntos de piezas idénticas que se repiten en una misma tumba (figuras 197, 210, 211, 230, 231) y un excepcional cántaro doble-silbato, de Monte Albán If (figura 205).

Del Golfo hay una serie importante de esculturas en barro del Clásico, de la cual destaca una monumental perteneciente al estilo de El Zapotal recientemente dado a conocer, 4 un conjunto de piezas relacionadas con el juego de pelota, provenientes tanto del Golfo como de la costa del Pacífico reunidas por su unidad temática y la mayor parte de ellas de una notable calidad artística. E1 arte huasteco está escasamente representado por cuatro liguras (figuras 281 a 284), pero con una escultura interesante por su representación dual, vida-muerte, de un anciano (figura 283).

Las obras pertenecientes a las diferentes fases del Clásico y Posclásico maya están agrupadas por cinco regiones: la costa del Pacífico, las tierras altas de Chiapas y Guatemala, la península de Yucatán, la isla de Jaina y las tierras bajas centrales. Entre los objetos en cerámica, se encuentra un vaso cilíndrico con una representación del juego de pelota, de gran belleza y notable interés iconográfico (figura 310); no podían faltar los elementos arquitecturales como una espiga en forma de personaje sentado (figura 296) y numerosas cabezas en estuco (figuras 317 a 322); una estela o altar cilíndrico presenta una inscripción jeroglifica que el autor interpreta como una fecha y el glifo de Tonina.

La única pieza del Caribe es el famoso asiento en madera publicado por

3 Phil C. Weigand, "The Ahualulco Site and the Shaft-Tomb Complex of the Etzatlan Area", in Betty Bell (ed.), The Archaeology of West Mexico, pp. 120-132, Sociedad de Estudios Avanzados del Occidente de México, Ajijic, Jalisco, 1974.

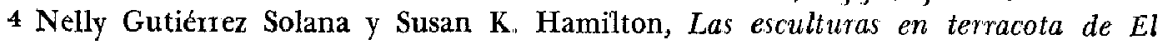
Zapotal, Veracruz, Universidad Nacional Autónoma de México, México, 1977. 
J. Walter Fewkes y adquirida por el museo en el siglo pasado (figura 332) perteneciente a la cultura Taino de Santo Domingo.

La mayoría de los estilos en cerámica, escultura y metalurgia de América Central y de los Andes septentrionales, están representados con objetos poco numerosos pero de gran valor artístico. Para los Andes Centrales, la colección está ordenada según las seis regiones acostumbradas y la secuencia cronológica "Aquí también el acervo es reducido, pero figuran piezas de calidad y valor excepcional, como un gran disco Chimú en plata repujada similar a otros dos conocidos (figura 428); el conjunto de tejidos de un bulto funerario Paracas (figuras 442, 443) o el tablero en plumas bicolores inca, formando parte de una gran serie dispersa ahora en todo el mundo y solamente cuatro de ellos conocidos.

Esas breves anotaciones permiten apreciar la importancia indiscutible de esa colección para los estudios del arte precolombino en general y mesoamericano en particular, para los cuales este libro puede considerarse como de consulta obligatoria, con las restricciones de que en varios casos la información quedó incompleta y de que en su mayor parte la colección sigue inédita.

La calidad de las fotos en negro y blanco y a colores es un fiel homenaje al valor artístico de las obras, y permite una clara apreciación de ellas; in. cluye además, un dibujo, cuando el desarrollo del motivo lo amerita. Los errores de edición son escasos: los cuadros cronológicos de las páginas 214 y 253 están invertidos; la figura 438 es otra foto de la misma pieza ilustrada en la figura 437, y por lo tanto la figura 438 no corresponde a la cédula 438; la ilustración a colores 310 queda invertida.

M-A. H.

Garcia Sáiz, Concepción. La pintura colonial en el Museo de América. I. La escuela mexicana. II. Los enconchados. Madrid, 1980.

La autora de estos libros se ha significado en los estudios de arte hispanoamericano, por el interés que ha mostrado hacia la historia de la pintura, disciplina en la cual está llamada a ser una autoridad. Respecto a la obra de los maestros que trabajaxon en lo que fue la Nueva España, las contribuciones que ha publicado hasta la fecha son de singular importancia, tanto por las novedosas noticias que ofrece, como asimismo por los juicios que le merecen los artistas y sus obras.

En el primer libro, Concepción García Sáiz se ocupa de las pinturas novoespañolas existentes en el Museo de América; si se tiene presente que éste es un catálogo de tales cuadros, se entiende el sentido que la autora dio tanto a la presentación como a la introducción de su estudio, en breves pero bien documentados escritos; otro tanto se puede repetir respecto a lo que informa sobre las colecciones que se encuentran hoy en el museo. Sin embar- 
go, llaman la atención los extensos y eruditos textos que redactó, para consignar las noticias conocidas sobre los artistas que están presentes en las salas mediante sus obras.

Considerable por su valor e importancia es el fondo de pintura mexicana con que cuenta el museo. La colección está constituida por cuadros anónimos, no exentos de interés, y por otros que firmaron sus autores. El siglo xviı está representado por un solo cuadro, ipero qué cuadrol; se trata de una más de las magníficas versiones que sobre El Divino Rostro, pintara el dominico Alonso López de Herrera. En realidad, la mayor parte de las telas allí existentes corresponden al arte barroco del xvin. En este orden de cosas el pintor mejor representado es Miguel Cabrera; si importantes son sus telas de temas religiosos, de mayor interés resultan los ocho cuadros que forman parte de una serie mayor, sobre las castas o tipos de habitantes de la Nueva España. En realidad son magníficas estas pinturas de Cabrera; se encuentran entre lo mejor que hizo. Le sigue en importancia por el número de obras, el enigmático y desigual pintor José de Páez. Una interesante composición sobre La Inmaculada, es el único cuadro de José de Ibarra que posee el museo, y quizá es mejor así; García Sáiz anota oportunamente el posible origen de la composición: un grabado del italiano Carlo Maratta . Del grupo de pinturas anónimas sobresalen las siguientes: El retrato de una monja, una Vista de la Alameda de México y varios cuadros referentes a las castas.

El segundo libro está dedicado a los cuadros "enconchados", que en número considerable posee el Museo de América, si bien las piezas allí reunidas proceden de otras instituciones como son el Museo Arqueológico Nacional y el Arqueológico de Valladolid. Concepción García Sáiz recoge, en la intro. ducción, las noticias existentes sobre este singular tipo de obras, mismas que algunos las consideran en el campo de la pintura, mientras que otros en el mal llamado de las artes industriales. Aunque sin fijar límites cronológicos precisos, se acepta en un consenso general que se trabajaron entre fines del siglo xvIr y primeros años del siguiente. Los únicos artistas que se han identificado en la factura especial de estas tablas se apellidaban González; parece ser que se trataba de toda una familia.

Las pinturas de los cuadros "enconchados", muestran dos temas preferen. ciales, uno religioso y el otro laico; en ambos casos se trabajaron los temas por series, aunque también los hubo individuales. En las series mundanas sobresale el tema de la Conquista de México; quizá no esté de más el recor. dar aquí la serie de la Conquista, existente en Buenos Âires.

Años atrás Genaro Estrada dio a conocer algunas obras de arte mexicano que localizó en España; otro tanto hizo Joaquín González Moreno, si bien él se dedicó al tema concreto de la Virgen de Guadalupe; con ello publicó, en 1959, una interesante iconografía guadalupana existente en la península. Dentro de esa línea están estos catálogos que ha trabajado Concepción García Sáiz, para dar a conocer el acervo artístico de México en España. Ojalá que su ejemplo cunda.

X. M. 
Kelemen, Pál. Vanishing Art of the Americas. Walder and Company. New York. 1977.

El ilustre crítico e historiador de arte Pál Kelemen, de origen húngaro, ha publicado el libro titulado Vanishing Art of the Americas, que podría traducirse como "Arte que desaparece en América". Es una hermosa obra, digna de ser publicada en español, ya que trata principalmente de arte colonial hispanoamericano.

Libro de gran interés para el especialista, resulta también sugerente para quien desea profundizar en nuestras raíces ancestrales. Es, además, dramático, pues aunque pretende descubrir, analizar y mostrar la personalidad expresiva de nuestras tierras, hace sentir a la vez el estado de incomprensión, abandono y hasta destrucción de tan importante patrimonio cultural, lo que justifica el título del libro como un arte que desaparece, se extingue o desvanece.

Arte que también se nos aleja cada día más en el tiempo, por lo que darse la mano con él es, más que un saludo, una despedida, ya que su presencia física, los ideales e intereses que tuvieron sus creadores y su íntimo y pro: fundo significado se van perdiendo en el devenir actual que quizá, justamente por su aceleración, tropieza, y en un momento dado tiene que desviar la mirada para olvidar que no supo ver lo que había en el camino.

En nueve capitulos, el libro nos hace viajar de norte a sur por América, con escalas en el adobe y la imaginería popular en pintura, las obras en madera y piedra de Nuevo México, la problemática de las minas y las mi. siones del norte de México, incluidos Monterrey, Saltillo y desde luego Zacatecas y Durango, sin pasar por alto lugares tan poco conocidos como son Concordia y Rosario de Sinaloa.

Se toca el tema, muy eruditamente, de un catafalco del siglo xviri, que se conserva en el museo de Toluca, pero sin olvidar monumentos tan significativos cuanto abandonados como la Contaduría de San Blas, en Nayarit. Nos asombramos ante algunas Andrean Village Churches, o "iglesias de pueblo", tan maravillosas como la de San Pedro Andahuaylillas, en Perú, con su rústico pero hidalgo exterior y el milagro del desierto que florece en su interior, pletórico de plástica pictórica y escultórica.

Para nuestro bélico siglo, no falta el tierno regaño de los "ángeles arcabuceros" de Perú y Bolivia, los que si dispusieran (como pueden disponer) de armas mayores, no estarían capacitados para usarlos sino para la Paz y sus amenazas teatrales, barrocamente dancísticas, que son tan sólo una deli. ciosa y bravucona americanada y también un buen deseo.

La obra trata también del tema de los textiles populares, cuya indigena agonía continental debería ser preocupación prioritaria, oficial o particular, de preservación patrimonial.

Finalmente quedamos entre pasmados y meditativos ante esos extraordinarios lenten altar veil, o mejor dicho "velos de cuaresma", ahora fuera de uso litúrgico por presiones de la "puesta al día", pero que en otro tiempo se usaron en Perú y Bolivia. Velos para ocultar el esplendor de los retablos 
dorados que en Semana Santa debían mostrarse apagados y tristes por la luctuosa conmemoración expresada en tonos morados; de ahí el tema principal del Calvario que inspiró estos lienzos que se hermanan y dialogan, plástica y hasta estéticamente, con el romántico y el gótico. Intemporalidad nada ajena al verdadero arte religioso $\mathrm{y}$, por consiguiente, a nuestro arte colonial.

Así, consideramos que el libro de Pál Kelemen, Vanishing Art of the Americas, de ser bien comprendido, nos enseña que, como contrapartida, nada desaparece del todo.

M. G, G

Reyes de la Maza, Luis. Ignacio Ramirez (El Nigromante). Bosquejos dramá. ticos. Gobierno del Estado de Guana. juato. 1982.

Dentro de la meritoria labor cultural del Gobierno del Estado de Guanajuato se publican los Bosquejos dramáticos, así llamados por su autor, el "ensayista y filósofo" Ignacio Ramírez, más conocido en sus dias, como "El Nigroman. te" El "Estudio Preliminar" es de Luis Reyes de la Maza, quien también llevó a cabo con gran conocimiento, amor y paciencia la faena de dar a estas obras la estructura teatral de la que carecían. Primero hubieron de paleo. grafiarse, y después, resolver el rompecabezas que implicaba aclarar qué personaje era el que hablaba, pues Ramírez no se había preocupado por señalar al actor que llevaba la voz. Reyes de la Maza, revisando una y otra vez los textos, pudo poner - repito- el nombre del protagonista en el parlamento correspondiente . Corrigió además la "pésima ortografía de Ramírez" y la puntuación; gracias a su esfuerzo es posible el que conozcamos, en una limpia y cuidadosa versión, la obra dramática del eminente iconoclasta del siglo xix.

En su apretado y por demás valioso estudio, Reyes de la Maza nos dice que las comedias y dramas de Ramirez se encontraron en un viejo archivo escrito en papel con sello de un juzgado, e impresos en un círculo los años de 1850 y 1851, años en que "El Nigromante" tenía treinta y dos o treinta y tres años de edad.

La aparición de estos Bosquejos dramáticos viene a ser un feliz descubrimiento que muestra un nuevo y desconocido aspecto de "El Nigromante", faceta a la que no aludieron ni Guillermo Prieto ni Ignacio Manuel Altamirano, su discípulo, el que mucho se enorgullecía de saber al dedillo la obra de su maestro, ni tampoco sus otros biógrafos Felipe Sánchez y Francisco Sosa, ya que de haberlas leído hubieran hecho hincapié en estos experimentos teatrales de Ramírez, en los que, abandonando toda solemnidad, no dejó títere con cabeza; hasta a don Joaquín Fernández de Lizardi "El Pensador Mexicano" le tocó su rasponcito. Seguramente Ramírez a nadie mostró estas sus diversiones; debió considerarlas como eso -como meros pasatiemposescritos para desahogar libremente su espíritu satírico, en esta ocasión, rebosante de chispa, bien sandunguero, henchidas de expresiones ingenuas, 
burlas a las normas morales de su tiempo que otorgan un enorme atractivo a sus comedias.

La obra teatral de Ramírez la constituyen veinticinco títulos. Reyes de la Maza recoge aquí comedias, dramas, una tragicomedia y los esbozos de otras obras que "El Nigromante" tuvo, al parecer, la idea de redondearlas más adelante. Las obras que figuran en la edición llevan los siguientes nombres: La caverna de Cacahuamilpa, El licenciado Juan Vena, El argumento de un drama, Un perro en barrio ajeno, Deudas de juego son deudas de honor, Los españoles en Capulhuac, La noche triste, Junio Bruto, Rosa, Pocahontas, Carolina, Gracias a unos jumentos todos quedan contentos, Iturbide, Serrano y Rosa, No hay en los consejos ciencia, Un mofador. De los apuntes que no tienen valor literario ni dramático, Reyes de la Maza sólo consigna el título: Carlos Flores, Los genizaros en tiempos de Selim el Yacur, La hija de un millonario o casamiento por amor, La hoja de servicios, Xóchitl, El Perico, Una pastorela casera, Un negociante en Mazatlán. En estas obras "El Nigromante" hizo alarde de talento, de imaginación, las inundó de "sal ática" como en esos años se decía y se demoró en la crítica social, sin olvidar en alguna ocasión la política.

Reyes de la Maza analiza a conciencia cada una de estas producciones de Ramírez: asunto, tramas, versificación -con esta última el autor hace lo que le viene en gana-, sentencia sobre su intrínseco valor literario, no deja de recalcar la intención de Ramírez de hacer una alegre sátira del romanticismo cuyo auge era manifiesto en esos años cincuenta; sin embargo, advierte Reyes de la Maza, que pese a la mofa, Ramírez cayó en la trampa romántica: trabajó con los mismos temas y arbitrios de esa escuela; su obra se resiente de idénticas fallas Los temas que trató son del todo románticos: amores encendidos y traicionados, infidelidades a granel, raptos, fugas, connatos de suicidios, celos, muertes, situaciones equívocas, asuntos cuyo manejo revela a Ramírez como un genuino costumbrista equiparable -según su crítico Reyes de la Maza- a un Guillermo o aun Ángel de Campo.

Siguiendo paso a paso al romanticismo, Ramírez cultiva asimismo el drama histórico $y$, al igual que los románticos, la fidelidad histórica le tiene sin cuidado, como puede advertirse en el Licenciado Juan Vena, pues su interés se centra en dejar mal parada a la época colonial y a los virreyes don Antonio de Mendoza y don Luis de Velasco. El tema histórico indigenista lo desenvuelve en La Noche Triste falseando a su sabor la historia, los personajes y las situaciones; tanto los españoles como los indígenas están apresados en un humorístico y trágico laberinto de amor y de pasión.

Además de los temas históricos nacionales, Ramírez se ocupó de la historia universal: Pacahontas y Junio Bruto, pero la anécdota y su desarrollo se le escaparon de las manos.

Blanco del sentido del humor de Ramírez fue la mujer idealizada por el romanticismo y, en México, venerada por poetas y editores del tiempo "Y así, mientras Mariano Galván, Vicente García Torres, Ignacio Cumplido rendían devoto homenaje en sus preciosos Calendarios, Panoramas, Presentes amistosos a las lindas señoritas mexicanas, dignas de todo respeto y admiración, 
Ramírez se solaza en presentarlas regocijadamente no como ángeles, sino con esa otra cara de la moneda: perversa y cruel que el romántico también exageró, es decir, en su fragilidad humana.

Para Ramirez, las mujeres - las señoritas mexicanas- no son delicadas, melindrosas, virtuosas, fieles; las protagonistas aqui, en sus Bosquejos, se pavonean como atrevidas, hipócritas, coquetas, ambiciosas; la virtud, por engorrosa, se la ponen de montera, el matrimonio es conveniencia, la pasión la disfrutan en su plenitud, fingen morir de amor, pero están siempre prontas a sustituir al amante perdido. Ramirez lleva su sarcasmo hasta poner en boca de una de esas admirables señoritas mexicanas -dirigidas a su amador- expresiones escatológicas bien populares. "Cuánto debe haberse reído "El Nigromante" de su sans-façon al hacer chunga del romanticismo y de sus heroinas! Todo se paga y en el pecado llevó la penitencia, pues sus obras hubo de guardarlas; no había compañía teatral que se atreviera a llevarlas a escena, a que se provocara un escándalo mayor que aquel que se produjera en la Academia de Letrán cuando Ramírez, en 1836, declaró "Dios no existe"; la puritana y burguesa sociedad lo hubiera anematizado ante su nuevo grito: "la virtud no existe".

En cambio hoy día, algunas de esas chispeantes comedias -aconseja Reyes de la Maza- merecen ser escenificadas, y dax a conocer "cuanto antes a un muy estimable comediógrafo mexicano que, por azares del destino había permanecido ignorado como tal"; especialmente debe ser aplaudida la comedia mejor lograda, El argumento de un drama.

Estas jacarandosas comedias de enredo de Ramírez invitan, desde luego, a la investigación, y cuyo resultado será un conocimiento más a fondo de la historia y el desarrollo de nuestro teatro.

A los valores de la obra teatral de Ramírez, añade Reyes de la Maza la sorprendente novedad de haberse adelantado "El Nigromante" a su siglo, pues en varias de sus comedias el teatro del absurdo, "distorsionando a to máximo situaciones, el conflicto con un desprecio absoluto de la lógica, los personajes en sus reacciones y diálogos poco tienen que rendirle a Ionesco".

Con este "Estudio Preliminar", el haber dado estructura teatral a las comedias y dramas de Ramírez, así como sus anteriores libros, Luis Reyes de la Maza nos confirma - sin hipérbole- que hoy por hoy es quien más sabe y entiende sobre el teatro mexicano del siglo xIx.

Por último, la edición del teatro de Ramírez es excelente. Se ilustra con viñetas y litografías de la época, varias tomadas de la obra del artista inglés Daniel Thomas Egerton y otras del litógrafo mexicano Casimiro Castro que se encuentran en el álbum México y sus alrededores (1855-1856). Litografías y viñetas (las mismas litografías reducidas) complementan y otorgan un mayor atractivo a la edición Bosquejos dramáticos.

C. D. y de O. 
Villaseñor Báez, Luis Francisco. La ar. quitectura del comercio en la cirdad de México. Disposición e Historia. México, Cámara Nacional de Comercio de la ciudad de México, 1982.

Un tema realmente novedoso dentro de la literatura sobre arquitectura en cierta manera escasa, que sin embargo ha visto aparecer este año la primera monografía sobre un arquitecto contemporáneo, es el libro escrito por Louise Noelle sobre Agustín Hernández. En el caso del trabajo de Villaseñor se aborda un tema novedoso que llama la atención sobre un género poco atendido: el local comercial.

Si el comercio significa nuestra época y si sus raíces son bien antiguas, Villaseñor nos plantea con gran claridad el problema desde la revisión de los antecedentes, bien se trate de los europeos y los mexicanos, en este caso con la revisión de las crónicas que nos hablan de los mercados como el de Tlatelolco donde son incrustados trozos de la crónica de Bernal Díaz, donde se nos ofrece una visión viva de la urbanística y la organización de la ciudad gemela a Tenochtitlan, todo inscrito dentro un contexto histórico revisado cuidadosamente en sus logros para alcanzar el sitio en la historia del país, lo que ahora es nuestro país.

El lúcido escritor revisa la conformación del recinto que había de dar a ese pueblo Tlatelolco, su sitio dentro de la historia del comercio. Los lugares desde los cuales provenían las mercaderias y por ende las riquezas, son consignados puntualmente. También considera a lo largo de su trabajo los giros comerciales que enriquecieron a los aztecas; tal es el caso de la venta de esclavos para el sacrificio de los dioses. En el caso de las rutas son consideradas diez, cada una con sus peculiaridades. Destaquemos la revisión que hace de la región de Tzin Tzun Tzan o la Mixteca, con cuyos productos se enriquecían los mercados de México y Tlatelolco.

En un apartado el autor consigna los elementos urbanos y arquitectónicos del tianguis indigena; para ello reflexiona sobre el papel que cumplen los centros ceremoniales, basándose en crónicas y testimonios de muy diversa índole, como la pintura de Diego Rivera en Palacio Nacional y la maqueta del Museo de Antropología.

La obra toda se anima con los claros dibujos de Alber to Beltrán, y asi las imágenes y el texto nos auxilian en la lectura y reconstrucción de la plaza mercado; el mercado, los locales en las casas señoriales donde se alojaban los sitios de compra-venta en la ciudad virreinal. En este apartado nos ilustramos con la cuidadosa revisión de los conceptos usados en la reorganización de la ciudad con la intervención de Alonso García Bravo, quien respetó las calles de agua como ha evidenciado la recuperación de la calle Corregidora y la de Alhóndiga, Otras calles mixtas con acequia o caño al centro. En las de tierra y en las plazas se concentró el comercio en torno a ellos, creando una metrópoli bulliciosa y ocupada cuyos nombres antiguos revelan la ocupación de sus habitantes. Desde mediados del siglo xvr existian las tiendas de Te- 
jada. La primera edificación construida para las transacciones comerciales era de planta triangular, donde se alojaban espléndidas tiendas complementadas con casa habitación como era habitual en esos años; similares características presentaban los portales de los cuales los del rumbo de Vizcaínas agrupaban a los ricos mercaderes que comerciaban con productos europeos y orientales. También fueron importantes los mercados diseminados en los diversos barrios de la ciudad.

Del aspecto que tenía la ciudad en el siglo xviIl da cuenta el arquitecto Villaseñor, refiriéndose al óleo de la colección del Museo Nacional de Historia. En ese sitio se alojaba el portal de mercaderes. También consigna el papel primordial que en el aspecto comercial cumplió el Parián y la Plaza de Santo Domingo. La primera fue también una construcción especificamente creada para alojar comercio de altura. La historia fue cuidadosamente revisada e interpretada, lo mismo acontece con el edificio de la aduana del pulque y la fábrica de tabacos, obra que cierra el periodo virreinal.

Los apartados que históricamente nos ligan con los tiempos actuales son del mayor interés; son consignados los aspectos urbanísticos y los nuevos estilos que responden a un cambio de ideología. Para ello el autor aprovecha las gacetas de las que extrae los ideales de la modernidad y con ello nos devuelve una imagen viva de la ciudad, renovada por los empeños de sus gobernantes y los trabajos de sus ideólogos; tal es el caso de Orozco y Berra, quien hace una revisión de los ramos de comercio en una lista y estadística que nos revela la importancia del comercio y su situación.

A ese esquema aparecen las tiendas departamentales que habrian de renovar los hábitos de compra y la arquitectura con la implantación de nuevos materiales y novedosa disposición de los departamentos. Es interesante señalar la manera como Villaseñor subraya la correspondencia entre los grandes edificios públicos - Palacio de Comunicaciones o Teatro Nacional-, así el Puerto de Liverpool, la Casa Boker o la joyería La Esmeralda casos logrados con pulcritud aunque sus funciones han cambiado. Entre las características que destaca es la disposición perimetral en torno a un patio cubierto de cristales. En el aspecto exterior los operadores dispuestos bajo marquesinas y con defensas tubulares, todo señalado con cornisas tubulares Varios casos son a nalizados con cuidado y son considerados los estucos, y muebles y los equipos recuperándonos una visión de esa arquitectura que significa la transición del siglo.

El último capítulo, uno de los más ricos y apretados del libro, va de 1910 a 1982; ahí se hacen importantes consideraciones sobre los logros de la ar. quitectura contemporánea; se consideran varios tipos de edificios: hoteles, gasolineras, mercados, tiendas de autoservicio, centros comerciales, todo inscrito dentro del desarrollo general de la arquitectura mexicana y de la metrópoli en sus vias y principales avenidas "Es considerado el cambio de destino de ciertas zonas habitacionales; tal es el caso de la colonia Juárez.

Análisis de los conjuntos como el América y Aristos; centros comerciales como el Plaza Universidad o Perisur, dan a este libro un verdadero sentido critico. 
El libro se cierra con una sintesis y se ofrecen interesantes perspectivas de un género que existe y condiciona nuestro vivir diario

M. D.

\begin{abstract}
Carrillo Azpeita, Rafael. Pintura mural de México La época prehispánica, el virreinato y los grandes artistas de nues. tro siglo. Editorial Panorama. México, 1981.
\end{abstract}

Constituye este pequeño libro de bolsillo, publicado en la Colección Panorama, una obra de difusión de la pintura mural de México desde la época prehispánica hasta nuestros días. Se puede afirmar que sus pretensiones van más allá de la obra de difusión, ya que es a la vez una buena introducción para los estudiantes de arte, puesto que a lo largo del texto se ofrecen importantes referencias bibliográficas que permitirán, a aquellos lectores que tengan interés en hacerlo, profundizar más en cada uno de los temas tratados.

Es éste un ambicioso ensayo que muestra la evolución de la pintura mural en México en las diferentes épocas históricas por las que ha atravesado, que incuestionablemente han dejado huellas imborrables en esta manifestación artística.

En el apartado de Antecedentes se hace referencia a que la pintura mural tiene sus raíces más antiguas en las pinturas que exornaban los muros de los templos y palacios de Bonampak, Cacaxtla, Teotihuacan, Monte Albán, Mitla, etcétera. Cita Rafael Carrillo al arqueólogo Ignacio Bernal para re" ferirse a la técnica del muralismo practicado en el pasado indigena vigorosa manifestación de la cultura de los pueblos mesoamericanos A través de nu. merosas citas destaca la capacidad de los tlacuilos, misma que los evangelizadores durante la Conquista supieron aprovechar para catequizar. Así, fray Pedro de Gante creó junto a la capilla de San José de los Naturales, lo que puede considerarse la primera escuela de bellas artes del hemisferio, y utilizó la diestra mano del indígena para producir imágenes de la iconografía de la nueva religión. Manuel Toussaint considera que el maestro más importante de esta primera escuela de pintura fue el mestizo, hijo de español e india tlaxcalteca, fray Diego Valadés. Se hace mención también a otros muchos pintores indígenas o mestizos de la escuela de fray Pedro de Gante, que alcanzara su apogeo a mediados del siglo xvr. Asienta a la vez, cómo se difundió la nueva religión en los muros de los conventos, templos y capillas, señalando que los murales más notables son los del convento de Epazoyucan, Hidalgo.

La lucha por la independencia de México dejó al pais con la economía desorganizada y la sociedad dividida. La nueva nación encaró graves dificultades internas y externas; las artes plásticas no gozaron del favor de los antiguos mecenas, principalmente del clero, por lo que la Academia de Bellas 
Artes de San Carlos de la Nueva España, fundada en 1781, entró en decadencia.

En 1843 se decidió la reorganización de la Academia de San Carlos. Llegó de Europa, para la enseñanza de la pintura, Pelegrín Clavé. Juan Cordero intentó la resurrección del muralismo en la cúpula de la capilla del Señor de Santa Teresa y en la de San Fernando; inclusive pintó en la Escuela Nacional Preparatoria un mural de inspiración positivista.

Por lo que respecta a la pintura mural contemporánea, Rafael Carrillo coincide con la mayoria de los historiadores del arte al considerarla "hija de la revolución mexicana". Afirma que la pintura mural contemporánea es consecuencia del pasado artístico, y que los pintores de murales transformaron la pintura liquidando la época del academismo; se pronunciaron por un arte monumental y público, tradicional y popular. La pintura mural tuvo que ser auspiciada por el gobierno y plasmarse en los edificios públicos.

Según el autor, la pintura mural contemporánea ha sido importante no sólo desde el punto de vista estético, sino también técnico. Por un lado aprovechó el uso del fresco y la encáustica, y por otro empleó nuevas técnicas y materiales. Fue David Alfaro Siqueiros quien comenzó esta innovación en Nueva York en 1936, en el Siqueiros Experimental Workshop: A Laboratory of Modern Techniques of Arts. También hay que considerar las experiencias de Orozco y Rivera, quienes emplearon bastidores movibles de acero y cemento para sus murales. "La multiplicidad de técnicas no se explica sin una producción muralista copiosa y continua. Puede decirse que desde 1922 hasta nuestros dias, no han dejado de hacerse murales... y que el número de artistas que hacen pintura mural es muy grande". El autor incluye en esta parte del texto datos biográficos de los principales muralistas contemporáneos, obras que para él son las más importantes.

Rafael Carrillo terminó su estudio un tanto abruptamente, ya que no hizo hincapié en lo que era su idea central: la secuencia del muralismo en las tres etapas del arte mexicano. El libro incluye ilustraciones en blanco y negro, y algunas en color, que permiten ejemplificar los temas tratados. Su pequeño índice no aclara mucho en cuanto al apartado "Antecedentes"; quizá valdría la pena incluir el final, después del breve corolario que sugiero, un indice onomástico y de lugares que sería de gran utilidad tanto para el estudiante como para el turista.

No obstante estos pequeños detalles, considero que esta obra cumple con su cometido. Por su lenguaje claro y accesible es un texto de utilidad, tanto a nivel de difusión del público en general, como a nivel introductorio paxa el estudiante de arte. Considero un acierto que los editores hayan publicado esta obra en español y en inglés, con lo que alcanzará, sin lugar a dudas, a mayor número de lectores nacionales y extranjeros.

Waltraut Rojas de Méndez. 